Die Tatsache, daß der WF-Antikörper keine oder höchstens minimale Agglutinationswirkung gegenüber Rickettsien ausübt, besagt noch nicht, daß dieser Immunkörper beim Fleckfieber therapeutisch ohne Bedeutung sei. Das Glykoproteid (glykolipoide Antigen) des Proteus X 19 ist, soweit bisher bekannt, für Kaninchen und für den Menschen von beträchtlicher Toxizität. Nach Ciuca und Mesrobeanu $\mathrm{u}^{24}$ sind $0,07 \mathrm{mg}$ des reinen Antigens für Kaninchen von 1,5 kg Gewicht deutlich toxisch - ein Befund, den wir bestätigen können-, und Braun und Unat ${ }^{25}$ fanden, daß beim Menschen die intravenöse Injektion noch geringerer Mengen (in Form von Proteus- $X$-19-Bakterien) Unwohlsein und Fieber hervorruft. Die Toxizität des von uns aus Rickettsien gewonnenen WF-Glykoproteids ${ }^{5,6}$ konnten wir noch nicht näher bestimmen. Indessen sind

${ }_{24}$ M. Ciuca u. L. Mesrobeanu, Rev. stiint. med. (rumänisch) 30, 114 [1939].

${ }_{25}$ H. Braun u. E. K. Unat, Istanbul Seririyati 26, 40 zahlreiche ähnliche Glykoproteide pathogener Mikroorganismen sehr wirksame Toxine, und es ist demnach nicht unwahrscheinlich, daß der WF-Antikörper in vivo die Funktionen eines Antitoxins ausübt. Unter diesem Gesichtspunkt wäre der Einfluß der Immunisierung mit dem O-Antigen von Proteus $X 19$ oder mit dem entsprechenden WF-Antigen von Rickettsien auf den Verlauf des menschlichen Fleckfiebers nochmals zu überprüfen ${ }^{26}$. Die aktive Fleckfieber-Immunisierung mit den bekannten Impfstoffen ergibt im allgemeinen beim Menschen Immunseren, welche Weil-Felix-negativ reagieren ${ }^{\mathbf{1 8}, 27}$. Es wäre daher in diesem Zusammenhang an eine Kómbination des Fleckfieber-Impfstoffes mit dem Proteus-X-19-Antigen oder dem entsprechenden Glykoproteid aus Rickettsien zu denken.

26 Vergl. H. Stutzer, J. Mikrobiol. (russ.) 6, 175 [1928].

27 Vergl. z. B. R. Meyer, Z. Immunitätsforschg. 103, $165[1943]$. [1944].

\title{
Über die Vermehrungs- und Ausbreitungsgeschwindigkeit des X-Virus im Blattparenchym
}

\author{
Von ERICH KöHLER \\ Aus dem Botanischen Institut für Virusforschung der Biologischen Zentralanstalt in Celle \\ (Z. Naturforschg. 2 b, 29-34 [1947]; eingegangen am 2. November 1946)
}

\begin{abstract}
Die- Geschwindigkeit, mit der sich das Kartoffel-X-Virus im Blatt-Parenchym anfälliger Wirtspflanzen ausbreitet, wurde durch vergleichende Messungen an kreisförmigen Infektionsherden verschiedenen Alters ermittelt. Die gefundenen Werte betragen rund 0,3 $\mathrm{mm}$ im Blatt der Tabaksorte Samsun, 0,2 mm im Blatt der Tabaksorte Xanthia und 0,1 mm im Blatt von Datura Stramonium innerhalb 24 Stunden. Im nervenständigen Parenchym erfolgt die Ausbreitung erheblich schneller, wodurch die stärkeren Abweichungen von der Kreisform zustandekommen.

Ferner wird gezeigt, daß die Vermehrung (Konzentrationszunahme) des X-Virus im geimpften Blatt unter bestimmten Voraussetzungen der Zunahme einer stetig wachsenden Kreisfläche gleichgesetzt werden kann und daß die Ausbreitung in den latenten Infektionsherden der Blätter von Atropa Belladonna mit derselben Geschwindigkeit erfolgt wie beim Samsun-Tabak.

Die Frage nach dem Mechanismus der Virusausbreitung im Parenchym wird kurz gestreift, sie bedarf noch eingehender Erörterung und experimenteller Prüfung.
\end{abstract}

\section{A. Die Ausbreitung im Einzelherd}

D ie Infektionsherde gewisser Stämme des Kartoffel-X-Virus sind am beimpften Blatt der Tabakpflanze, wie seit langem bekannt, durch die nekrotischen Ringe gekennzeichnet, die konzentrisch zum Mittelpunkt des einzelnen Infektionsherdes angelegt werden. Wie in einer unlängst erschienenen Abhandlung ${ }^{1}$ von mir dargetan wurde, kann man diese nekrotischen Ringe als die Grenzmale betrachten, bis zu denen das Virus in einem bestimmten Zeitpunkt vorgedrungen ist. Sie entstehen auf einen noch nicht näher definierten vermutlich thermischen - Reiz hin in einer be-

1 E. Köhler, Über die Bildung nekrotischer Zonen an virusinfizierten Tabakblättern. Zugleich ein Beitrag zur Frage der Virusbewegung im Blattparenchym. Phytopathol. Z. 15, 24 [1944]. 
stimmten Zone der Ausbreitungsperipherie des Virus, die ich als Empfindlichkeitszone (EZ) bezeichnet habe. Da die EZ mit der Ausbreitungsperipherie des Virus sich fortgesetzt vom Herdmittelpunkt entfernt, können bei Wiederholung des Reizes nacheinander mehrere konzentrische Ringe entstehen.

Wenn man in bestimmten Zeitabständen Impfungen an physiologisch vergleichbaren Blättern oder noch besser an den beiden Hälften eines und desselben Blattes vornimmt, so erhält man Infektionsherde verschiedenen Alters mit unterschiedlich fortgeschrittener EZ. Tritt nun ein Reiz ein, der die Nekrosenbildung auslöst, so bekundet sich die jeweilige Lage der EZ durch Ringe verschiedener Größe. Die Differenz der Radien der von den Ringen umschlossenen Kreise entspricht der von der Empfindlichkeitszone und damit dem Virus in der Zeit zwischen den beiden Impfungen zurückgelegten Strecke, woraus sich die durchschnittliche Ausbreitungsgeschwindigkeit des Virus in der Zeiteinheit leicht berechnen läßt.

\section{Erste Feststellung (Tab. 1)}

Verimpfung des X-Virus (Stamm Us $/ r$ ) auf Blätter des Samsun-Tabaks mit der Blatthälftenmethode.

Rechte Hälfte, durch Einreiben beimpft am 23. Sept., linke Hälfte, durch Einreiben beimpft am 27. Sept., jeweils zur gleichen Tageszeit.

In der Nacht vom 1. zum 2. Oktober haben sich auf beiden Hälften stark nekrotische Ringe um die Infektionsherde gebildet. Der Durchmesser der Ringe wurde am 2. Oktober auf die Weise ermittelt, daß bei jedem Ring mit der Lupe zwei Durchmesser in $1 / 10 \mathrm{~mm}$ gemessen wurden, nämlich der größte und der dazu senkrecht stehende. Daraus wurde der mittlere Durchmesser errechnet. Nachstehend die so gewonnenen Werte der Ringdurchmesser bei zwei Blättern (in $\mathrm{mm}$ ):

\section{Blatt 1: Messungen*an Blatt 2: Messungen an je 13 Herden je 10 Herden} Tag der
Impfung: 23. Sept. 27. Sept.

\begin{tabular}{ll}
4,1 & 2,1 \\
4,3 & 2,3 \\
4,5 & 2,1 \\
5,4 & 2,1 \\
4,8 & 2,1 \\
4,4 & 2,2 \\
4,5 & 2,1 \\
5,1 & 2,0 \\
4,7 & 2,3 \\
4,7 & 2,1 \\
3,9 & 2,2 \\
4,7 & 2,4 \\
4,3 & 2,2 \\
\hline
\end{tabular}

23. Sept. 27. Sept.

$\begin{array}{ll}4,6 & 1,9 \\ 4,0 & 2,0 \\ 4,6 & 1,7 \\ 4,0 & 1,8 \\ 4,8 & 2,4 \\ 4,9 & 1,9 \\ 3,9 & 2,2 \\ 3,6 & 2,0 \\ 5,0 & 1,7 \\ 4,0 & 2,0\end{array}$

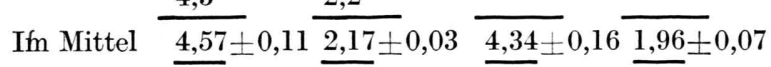

* Frl. Dr. R. Eicke danke ich für die Mithilfe bei der Ausführung der Messungen.
Differenz

der Durchmesser $\quad 2,40 \pm 0,115 \mathrm{~mm} \mathrm{2,38 \pm 0,17 \textrm {mm }}$ Differenz der Radien $\quad 1,20 \pm 0,06 \mathrm{~mm} \mathrm{1,19 \pm 0,085 \textrm {mm }}$ Ausbreitungsgeschwin-

digkeit je Tag demnach $\underline{\underline{0,3}} \pm 0,014 \mathrm{~mm} \underline{\underline{0,3}} \pm 0,021 \mathrm{~mm}$ Das Virus legt demnach bei seiner Ausbreitung im Parenchym täglich eine Strecke von rund $0,3 \mathrm{~mm}$ zurück.

\section{Zweite Feststellung (Tab. 2)}

Verimpfung des X-Stammes Us/ $r$ auf Blätter der Tabaksorte Xanthia. Vergleichbare Blätter verschiedener Pflanzen desselben Satzes wurden am 23. April und am 29. April auf ganzer Fläche durch Einreiben geimpft.

A. Blätter beimpft am 29. April

Werte (Durchmesser) in $\mathrm{mm}$

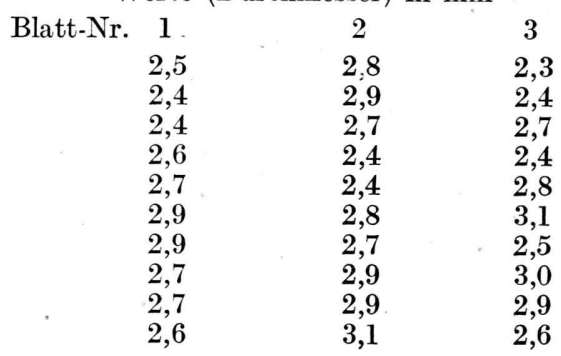

Im Mittel $\underline{2,64} \pm 0,056 \underline{2,76} \pm 0,07 \quad \underline{2,67} \pm 0,087$

Mittelwert $2,69 \overline{ \pm 0,0413 \mathrm{~mm}}$

$r_{1}=1,35 \pm 0,02 \mathrm{~mm}$

B. Blätter beimpft am 23. April

\begin{tabular}{cccc} 
Blatt-Nr. & 1 & 2 & 3 \\
& 5,5 & 6,2 & 4,7 \\
5,6 & 5,4 & 5,2 \\
6,2 & 5,8 & 5,0 \\
5,4 & 5,9 & 4,6 \\
5,9 & 5,2 & 5,1 \\
5,8 & 5,7 & 5,0 \\
5,1 & 5,4 & 5,3 \\
5,2 & 4,9 & 4,9 \\
5,4 & 5,6 & 4,8 \\
5,2 & 5,7 & 5,2 \\
Im Mittel & $5,53 \pm 0,11$ & $5,58 \pm 0,12$ & $\underline{4,98} \pm 0,07$ \\
Mittelwert & $5,36 \pm 0,076 \mathrm{~mm}$ \\
\multicolumn{4}{c}{$r_{2}=$} \\
\cline { 2 - 3 }
\end{tabular}

Daraus ergibt sich die Differenz:

$$
r_{2}-r_{1}=2,68-1,35=1,330 \pm 0,043 \mathrm{~mm}
$$

Differenz pro Tag $=1,33: 6=\underline{\underline{0,22}} \pm 0,007 \mathrm{~mm}$

Die Ausbreitungsgeschwindigkeit ist also etwas geringer als bei unserer ersten Feststellung, hält sich aber innerhalb derselben Größenordnung. Vermutlich ist die Differenz darauf zurückzuführen, daß die Virusausbreitung im Parenchym des Xanthia-Blattes etwas langsamer fortschreitet als in dem des Samsun-Blattes. Sie kann aber auch darauf beruhen, daß die Ausbreitung in Abhängigkeit vom 
physiologischen Zustand des Blattes und von den Außenbedingungen gewissen Schwankungen unterworfen ist. Hinlängliche Untersuchungen über den möglichen Umfang derartiger Schwankungen stehen noch aus.

Im vorstehenden wurden nur solche Herde berücksichtigt, die eine mehr oder weniger ideale Kreisbildung erkennen ließen. In der oben genannten Abhandlung wurde bereits darauf hingewiesen, daß starke Abweichungen von der Kreisform eintreten, wenn die Herde sich im Bereich eines Nervs entwickeln, und zwar deshalb, weil die Virusausbreitung in dem dem Nerv folgenden sogenannten Leitparenchym mit erhöhter Geschwindigkeit vor sich geht. Über die im Leitparenchym ermittelten Ausbreitungsgeschwindigkeiten werden erst in einer später erscheinenden Abhandlung nähere Angaben gemacht werden können, doch kann schon jetzt gesagt werden, daß sie ein Mehrfaches der Ausbreitung im übrigen Parenchym betragen.

\section{Dritte Feststellung (Tab.' 3) ${ }^{7}$}

$\mathrm{X}-\mathrm{Stamm} \mathrm{Us} / \boldsymbol{r}$ auf Datura Stramonium. Mittlere Durchmesser der größten Einzelherde, gemessen am 19. März.

\begin{tabular}{cc} 
Impfung vom 10. März & Impfung vom 7 . März \\
1,60 & 2,45 \\
1,60 & 2,30 \\
1,55 & 2,60 \\
1,40 & 1,85 \\
1,65 & 2,25 \\
1,55 & 2,75 \\
1,70 & 2,20 \\
1,65 & 1,95 \\
1,50 & 1,85 \\
1,60 & 2,00 \\
\hline 15,80 & 22,20
\end{tabular}

Im Mittel $\quad 1,58 \pm 0,017 \mathrm{~mm}$ Im Mittel 2,22 $\pm 0,099 \mathrm{~mm}$ demnach $r_{1}=\overline{0,79} \pm 0,014 \mathrm{~mm} \quad r_{2}=\overline{1,11} \pm 0,049 \mathrm{~mm}$ Differenz $r_{2}-r_{1}=0,32 \pm 0,051 \mathrm{~mm}$ (in 3 Tagen) somit Ausbreitung in $1 \mathrm{Tag}=0,11 \pm 0,017 \mathrm{~mm}$.

Demnach breitet sich das Virus bei Datura Stramonium etwas langsamer aus als beim Tabak.

\section{Erörterung zu Abschnitt $A$}

Die gewonnenen Werte sind sehr niedrig im Vergleich zu denen, die sich früher bei Ermittlung der Virusausbreitung in Blättern, Blattstielen und Stengeln mancher Objekte ergeben hatten. Es leg-

2 Vergl. die Zusammenfassung von C. W. Bennet, The relation of viruses to plant tissues. Bot. Rev. 6, 427 [1940].

3 Vergl. E. Köhler, Beiträge zur Kenntnis der Viruswanderung in der Pflanze, Biol. Zbl. 62, 203 [1942]. Dort auch Literatur. ten zurück: Das Streak-Virus ven Zea Mays im Blatt dieser Pflanze 20-40 cm in 2 Stcn. (Store y 1926); das Curly Top-Virus der Beta-Rüben im Blattstiel dieser Pflanze $10-21 \mathrm{~cm}$ in $1 / 2$ Stde. (Severin 1924); dasselbe Virus im Stengel von Nicotiana Tabacum $2,5 \mathrm{~cm}$ in 1 Stde. (Bennet 1934); ein Tomatenmosaik im Stengel von S. lycopersicum $17,8 \mathrm{~cm}$ in 1 Stde. (Kunkel 1939). In allen diesen Fällen handelt es sich um eine im Phloem sich abspielende Massenströmung, die dem Assimilate-Transport dient ${ }^{2}$. Das Vordringen des Virus im Parenchym ist sicher ganz anderen Gesetzmäßigkeiten . unterworfen. Daß die Viruspartikel viel zu $\operatorname{grc} \beta$ sind, um die Mikrocapillaren der Zellwände zu passieren, ist als eine gesicherte Feststellung anzusehen ${ }^{3}$. Das Virus ist daher bei seinem Vordringen von Zelle zu Zelle ganz auf die engporigen Plasmaverbindungen (Plasmodesmen) angewiesen, die die Zellwände in größerer oder geringerer Häufigkeit durchsetzen. Es fragt sich, ob die Partikel diese off $€$ nbar mit dichtem Plasma erfüllten Gänge durch Diffusion oder eine andere Art molekularer Wanderung überwinden können. Nach Messungen an elektronenoptischen Aufnahmen ${ }^{4}$ sind die Partikel des X-Virus ähnlich dem Tabakmosaikvirus fadenförmig; genauere Anछaben über die Dimensionen scheinen noch nicht vorzuliegen. Da aber die Parenchymausbreitung des TM-Virus sicher denselben Gesetzmäßigkeiten folgt, dürfen wir hier die bekannten Dimensionen dieses Virus einsetzen, obgleich die Einheiten des X-Virus zarter gebaut sind. Die Länge des einfachen TM-Moleküls beträgt ca. $150 \mathrm{~m} \mu$, die des doppelten $300 \mathrm{~m} \mu$. Der Durchmesser der Plasmodesmen im Parenchym kann auf etwa $200 \mathrm{~m} \mu$ geschätzt werden ${ }^{5}$.

Die Annahme, daß die TM-Partikel eine molekulare Wanderung durch diese relativ sehr langen und wahrscheinlich dicht mit Plasma erfüllten Kanäle ausführen, scheint auf Schwierigkeiten. zu stoßen, wenn man die bekannten Vorstellungen von Fre y-Wyssling ${ }^{6}$ über einen reticulardispersen Aufbau des Cytoplasmas zu Hilfe nimmt, da in einem derartigen Medium mit einem sehr beträchtlichen Diffusionswiderstand zu rechnen ist. Nimmt

4 Solche Aufnahmen wurden von G. A. Kausche bei seinem Vortrag auf der Virustagung der Biologischen Reichsanstalt am 23. Jan. 1943 in Berlin-Dahlem projiziert. (Vergl. auch H. Ruska, Arch. Virusforschg. 2, 481 (Abb. 2) [1943]).

5 Vergl. H. Lundegardh in Handb. d. Pflanzenanatomie Bd. 1, S. 131.

6 Frey-Wyssling, Submikroskopische Morphologie des Protoplasmas und seiner Derivate. Berlin 1938. 
man die Schlußfolgerungen Mühldorfs ${ }^{7}$ hinzu, so erscheinen diese Schwierigkeiten nicht geringer. Nach ihm befindet sich das Plasma in den Plasmodesmen für gewöhnlich in einem ,,fast gelartigen Zustand“. „Die Kanäle in den Wänden sind also genügend fest zugestopft, um einen freien Austausch des Cytoplasmas zu verhindern“. Hr. FriedrichFreksa hat es freundlicherweise übernommen, die Frage am Schlusse dieser Arbeit zu erörtern.

Keinen größeren Schwierigkeiten scheint die Annahme zu begegnen, daß das Virus die Plasmodesmen durch Wachstum überwindet, denn es ist anzunehmen, daß in den Plasmodesmen die für die Virussynthese erforderlichen Bausteine (Teilkomplexe des Virusmoleküls) wie im übrigen Plasma bereitliegen. Auch im Lumen der Zelle, insbesondere in dem dichteren, wandständigen Plasma mag die Ausbreitung des Virus durch Wachstum erfolgen, wobei die neu entstehenden Viruseinheiten als ein das Plasma durchsetzendes loses Netzwerk untereinander im Zusammenhang bleiben könnten. Als zweites Ausbreitungsmittel kommt im ZellLumen dann noch die Plasmaströmung in Betracht, die für einen schnelleren Transport der Viruspartikel geeignet ist. Über deren mögliches Ausmaß sind wir freilich z. Zt. noch recht unzulänglich unterrichtet.

\section{B. Analyse der Vermehrungskurve}

Man kann die Ausbreitungsgeschwindigkeit im Parenchym auch noch auf einem anderen Wege bestimmen, indem man nämlich die Konžentrationszunahme im eingeriebenen Blatt ermittelt. Dies zeigt das folgende Beispiel.

Am 6. Dezember wurden 5 kleinere, in Tonköpfen gezogene Pflanzen von Atropa Belladonna an ausgewachsenen vergleichbaren Blättern unter Verwendung von Karborundpuder mit dem nekrotisierenden Stamm Cs 44 des X-Virus beimpft und unter der Wasserleitung gut abgespült. In verschiedenen Zeitabständen wurden die aus den Blättern ausgepreßten Sammelsäfte je einer Pflanze auf zwei aufeinander folgende Blätter von 3 Tabakpflanzen (Samsun) verimpft, um das ungefähre Ansteigen der Viruskonzentration in den Atropa-

7 A. Mühldorf, Das plasmatische Wesen der pflanzlichen Zellbrücken. Beihefte z. Bot. Zbl. 54 (Abt. A), 171, 324 [1937].

8 Wenn Sheffield (Ann. Appl. Biol. 23, 498 [1936]) die Feststellung machte, daß bei Impfung einzelner Gewebszellen mit der Mikropipette die Infektion nur bei $15-17 \%$ der Fälle in Gang kam, so wäre für die Deutung blättern mit Hilfe der Einzelherd-Zählung festzustellen (vgl. ${ }^{9}$ ). Die Zahl der auf den Testpflanzen exschienenen Einzelherde war anfangs sehr gering, augenscheinlich vermehrt sich das Virus in den Blättern der Tollkirsche nur sehr langsam. Dazu kommt noch, daß an diesen Blättern keinerlei Krankheitssymptome zum Vorschein kommen, die Infektion also latent bleibt. Das Gesamtergebnis der Zählung ist aus Tab. 4 ersichtlich.

\begin{tabular}{|c|c|c|c|c|c|c|c|}
\hline Impfdatum & $\begin{array}{c}\text { Anzal } \\
\text { oberes oder } \\
\text { unteres } \\
\text { Blatt }\end{array}$ & $\begin{array}{l}1 \text { Ei } \\
\text { Test- } \\
\text { pfl. } \\
\text { Nr.1 }\end{array}$ & $\begin{array}{c}\text { nzel. } \\
\text { Test- } \\
\text { pfl. } \\
\text { Nr.2 } \\
\end{array}$ & $\begin{array}{l}\text { erd } \\
\text { Test- } \\
\text { pfl. } \\
\text { Nr. } 3 \\
\end{array}$ & $\begin{array}{c}\text { Sum- } \\
\mathrm{me}\end{array}$ & $\begin{array}{l}\text { - korrig. } \\
\text { Werte }\end{array}$ & $\begin{array}{l}\text { berech. } \\
\text { Werte }\end{array}$ \\
\hline \multirow{3}{*}{$\begin{array}{l}\text { sogleich nach } \\
\text { dem Impfen }\end{array}$} & unt. Bl. & 2 & 2 & 1 & 5 & & \\
\hline & ob. Bl. & 6 & 3 & 4 & 13 & & \\
\hline & & & & & 18 & 0 & 0 \\
\hline \multirow{3}{*}{ nach 5 Tagen } & unt. Bl. & 6 & 5 & 3 & 14 & & \\
\hline & ob. Bl. & 8 & 2 & 4 & 14 & & \\
\hline & & & & & 28 & 10 & 7 \\
\hline \multirow[t]{3}{*}{ nach 10 Tagen } & unt. Bl. & 4 & 7 & 3 & 14 & & \\
\hline & ob. Bl. & 8 & 11 & 7 & 26 & & \\
\hline & & & & & 40 & 22 & 27 \\
\hline \multirow{3}{*}{ nach 15 Tagen } & & & c & & & & \\
\hline & $\begin{array}{l}\text { unt. Bl. } \\
\text { ob. Bl. }\end{array}$ & $\begin{array}{r}6 \\
16\end{array}$ & $\begin{array}{r}6 \\
15\end{array}$ & $\begin{array}{l}10 \\
31\end{array}$ & $\begin{array}{l}22 \\
62\end{array}$ & & \\
\hline & & & & & 84 & 66 & 64 \\
\hline \multirow[t]{2}{*}{ nach 29 Tagen } & unt. $\mathrm{Bl}$. & 46 & 40 & 45 & 131 & & \\
\hline & ob. Bl. & 113 & 30 & 55 & $\underline{198}$ & & \\
\hline & & & & & 329 & 311 & 238 \\
\hline
\end{tabular}

Tab. 4. Anstieg der Viruskonzentration in Blättern von Atropa Belladonna nach Beimpfung mit dem Stamm Cs 44 des X-Virus.

Anm.: Für die statistische Beurteilung ist die Feststellung wichtig, daß sich die oberen Blätter fast ausnahmslos anfälliger erwiesen als die unteren.

Aus den Summenwerten ist die obere Kurve von Abb. 1 konstruiert; auf der Abszisse ist die Zeit in Tagen, auf der Ordinate die Anzahl der Einzelherde aufgetragen. Diese empirische Kurve gibt nun aber kein ganz getreues Bild von der Zunahme der Viruskonzentration, da sie die Tatsache unberücksichtigt läßt, daß nur wenige Teilchen einen ,Treffer" verursachen: Nur solche Teilchen dürfen aber berücksichtigt werden. Ihre Anzahl dürfte demWert 0

der negativen Fälle m. E. auch die Möglichkeit in Betracht zu ziehen, daß die Plasmodesmen nicht immer alle zum Virusaufbau erforderlichen Grundbaustoffe enthalten. Die geimpfte Zelle selbst könnte dabei empfänglich sein und die Infektion bliebe auf sie lokalisiert.

9 E. Köhler, Über die unterschiedliche Vermehrungsgeschwindigkeit von Stämmen des Kartoffel-X-Virus. Zbl. Bakt. (II) 104, 401 [1942]. 
sehr nahe kommen. Die Kurve muß daher korrigiert werden, indem die Summenwerte durchweg um den Anfangsbetrag, der 18 Einheiten beträgt, gekürzt werden. Man erhält dann die korrigierten Werte, wie sie der vorletzten Säule von Tab. 4 zu entnehmen sind; aus ihnen wurde die untere Kurve (II) konstruiert.

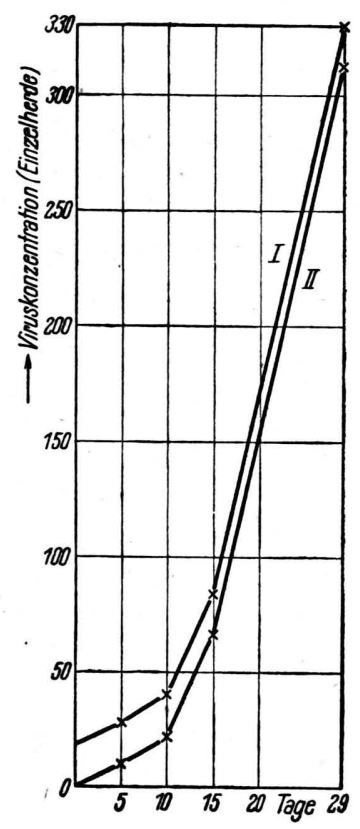

Abb. 1. Erklärung im Text.

Die einzelnen Infektionsherde entwickeln sich kreisförmig. Dies lehrt die von uns oben betrachtete Zonenbildung, wie sie u. a. bei nektrotisierenden Stämmen des X-Virus zu beobachten ist. Wenn nun die Vorstellung richtig ist, daß das Virus die gesamte von ihm beschlagnahmte und sich ständig ausdehnende Kreisfläche des Einzelherdes zu seiner Vermehrung ausnützt, so ist zu erwarten, daß die Vermehrung des Virus in ihm denselben mathematischen Beziehungen folgt wie die Ausdehnung einer Kreisfläche.

Auf Abb. 2 ist die Zunahme einer Kreisfläche kurvenmäßig dargestellt. Auf der Abszisse ist der Radius in Zuwachsbeträgen von $1,5 \mathrm{~mm}$, auf der Ordinate die entsprechende Kreisfläche (nach der Formel $r^{2} \pi$ ) in $\mathrm{mm}^{2}$ eingetragen. Wenn man mit einem Zuwachs des Einzelherdradius von 1,5 mm in 5 Tagen rechnet, wie er dem oben erwähnten Befund beim X-Virus am Samsun-Blatt entspricht, und die zugehörigen korrigierten Werte unserer Tabelle in das System einzeichnet, so ergibt sich eine aus- gezeichnete Übereinstimmung; die eingezeichneten Punkte fallen unmittelbar neben die Kurvenlinie. Dies besagt erstens, da $ß$ die Konzentrationszunahme dem Produkt $r^{2} \pi$ entspricht und daß zweitens der tägliche Zuwachs des Einzelherdradius im Atropa-Blatt tatsächlich 0,3 $\mathrm{mm}$ beträgt. Der nach 29 Tagen gewonnene Wert zeigt eine stärkere Abweichung; vermutlich die Folge eines Fehlers, darauf beruhend, daß bei dem späteren Datum die Empfindlichkeit der Testpflanzen gegen früher erhöht war.

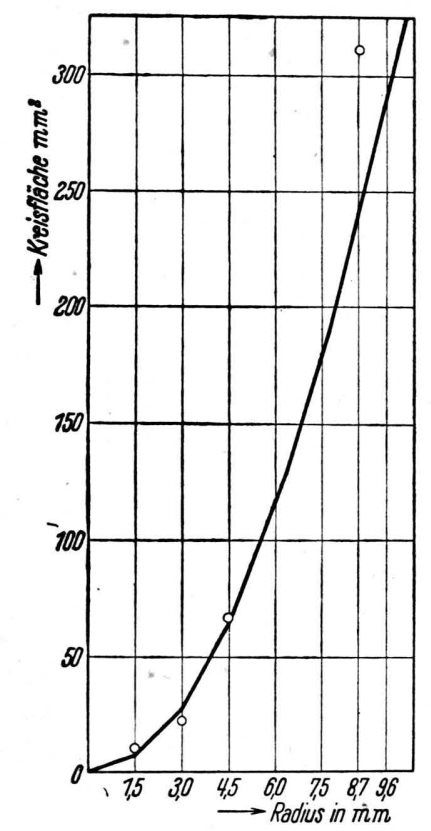

Abb. 2. s. Erklärung zu Tab. 4.

Daß die Virusvermehrung der Formel der sich stetig ausdehnenden Kreisfläche folgt, ist selbstverständlich nur dann zu erwarten, wenn sich die Einzelherde im Wachstum gegenseitig nicht behindern, was bei zu dichter Infektion der Fall ist; denn dann gehen die Einzelherde frühzeitig ineinander über und die Zunahme der Viruskonzentration je Herd ist geringer. Man wird also die aufgewiesene Gesetzmäßigkeit nur unter der Voraussetzung erwarten dürfen, daß die Einzelinfektionen hinreichend zerstreut erfolgen, was einerseits von dem Grad der Infektionsbereitschaft des Blattes, andererseits von der Viruskonzentration der Impfflüssigkeit abhängt.

$\mathrm{Ob}$ der oben festgestellte relativ langsame Konzentrationsanstieg bei Atropa darauf beruht, daß nur sehr wenige Infektionen zustande kommen oder 


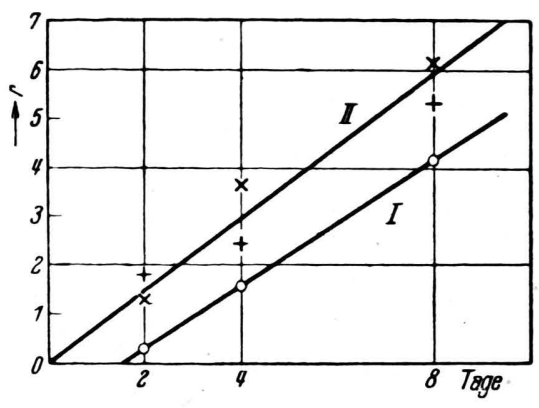

Abb. 3. Anstieg der Viruskonzentration in Tabakblättern nach deren Beimpfung mit den Stämmen Cs 37, Us und Bf des X-Virus.

Zeichenerklärung zu Ább. 3.

$\begin{array}{ll}\text { Stamm Bf } & \bigodot \\ \text { Stamm Us } & \times \\ \text { Stamm Cs 37 } & +\end{array}$

darauf, daß die Virusdichte im Infektionsherd sehr niedrig bleibt, wäre noch zu ermitteln. Da die Infektion latent ist, läßt sich diese Frage nicht mit demselben Verfahren prüfen wie bei anderen Wirten.

\begin{tabular}{|c|c|c|c|}
\hline $\begin{array}{l}\text { Virus- } \\
\text { Stamm }\end{array}$ & $\begin{array}{l}\text { Zeit in } \\
\text { Tagen }\end{array}$ & $\begin{array}{c}r^{2} \pi \\
\text { (gefunden) }\end{array}$ & $r$ \\
\hline Cs 37 & $\left\{\begin{array}{l}2 \\
4 \\
8\end{array}\right.$ & $\begin{array}{r}9,7 \\
18,0 \\
88,6\end{array}$ & $\begin{array}{l}1,8 \\
2,4 \\
5,3\end{array}$ \\
\hline Us & $\left\{\begin{array}{l}2 \\
4 \\
8\end{array}\right.$ & $\begin{array}{r}5,3 \\
40,8 \\
116,8\end{array}$ & $\begin{array}{l}1,3 \\
3,6 \\
6,1\end{array}$ \\
\hline $\mathrm{Bf}$ & $\left\{\begin{array}{l}2 \\
4 \\
8\end{array}\right.$ & $\begin{array}{r}0,3 \\
7,8 \\
53,4\end{array}$ & $\begin{array}{l}0,3 \\
1,6 \\
4,1\end{array}$ \\
\hline
\end{tabular}

Tab. 5. S. Erklärung zu Abb. 3.

In früheren vergleichenden Versuchen (1942) bestimmte ich die Vermehrungsgeschwindigkeit bei den drei nekrotisierenden X-Stämmen Cs 37, Us und $\mathrm{Bf}$ in eingeriebenen Tabakblättern. Wir wollen prüfen, ob die damals gewonnenen Werte gleichfalls der Formel $r^{2} \pi$ entsprechen. Wir brauchen aus ihnen nur die Werte für $r$ zu berechnen (Tab.5). Tragen wir auf der Abszisse die Zeit (in Tagen) und auf der Ordinate die Werte für $r$ ein (Abb.3), so müssen diese auf einer Geraden liegen. Wie man sieht, stimmt das Verhalten von Bf mit dieser Forderung sehr gut überein (Gerade I). Bei den anderen Stämmen (Gerade II) sind die Abweichungen größer, dürften aber noch in den zulässigen Grenzen liegen. Jedenfalls sprechen auch diese Daten im ganzen für die Richtigkeit unserer obigen Ableitungen.

\section{Zur Abschätzung der Diffusionsgeschwindigkeit von Viruss:offan durch die Plasmodesmen.}

(Bemerkung der Redaktion zu vorstehender Arbait.)

Herr $\dot{\mathrm{K}}$ öhler wirft dieFrage auf, wie rasch die Diffusion eines Virusstoffes von einer Zelle zur nächsten durch die Plasmodesmen erfolgt. Die Länge der Plasmodesmen bei Tabakpflanzen beträgt nach einer Arbeit von L. G. Livingston ${ }^{10}$ etwa $2 \times 10^{-4} \mathrm{~cm}$. Die Diffusionskonstante des Tabakmosaikvirus, das dem X-Virus der Kartoffeln ähnlich ist, hat in Wasser bei $20^{\circ}$ nach den Messungen von Bergold ${ }^{11}$ einen Wert von $4,4 \times 10^{-8} \mathrm{~cm}^{2} / \mathrm{sec}$. In der Pflanzenzelle ist entsprechend der höheren Viscosität des. Plasmas eine kleinere Diffusionskonstante anzunehmen. Im Plasma der Rhizomzellen von Chara wurden von J. Pekarek ${ }^{12}$ Werte von etwa dem zehnfachen der Viscosität des Wassers gefunden. Unter der Annahme, daß das Plasma der Plasmodesmen besonders dicht ist, kann man dafür einen Wert des hundertfachen der Viscosität des Wassers ansetzen, dann hätte die Diffusionskonstante $D$ des TMV darin einen Wert von $4 \times 10^{-10} \mathrm{~cm}^{2} / \mathrm{sec}$. Unter Annahme dieser Werte läßt sich die Größenordnung der Diffusionszeit $t$ nach der von Einstein für die Brownsche Molekularbewegung aufgestellten Formel $t=x^{2} / 2 D$ abschätzen, wobei $x$ die Länge des Diffusionsweges ist. Danach ergibt sich $t=\frac{4 \times 10^{-8}}{8 \times 10^{-10}}=50 \mathrm{sec}$.

Aus dieser Abschätzung geht hervor, daß die Diffusion ausreicht, um selbst bei einer hohen Viscosität die Geschwindigkeit der Ausbreitung von Zelle zu Zelle zu erklären.

Hrn. Köhler danke ich für den Hinweis auf die Arbeit von Livingston.

H. Friedrich-Freksa.

10 Amer. J. Bot. 22, 75 [1935].

11 G. Bergold u. G. Schramm, Z. Naturforschg. 2b, erscheint demnächst.

12 Protoplasma 17, 1 [1932]. 